
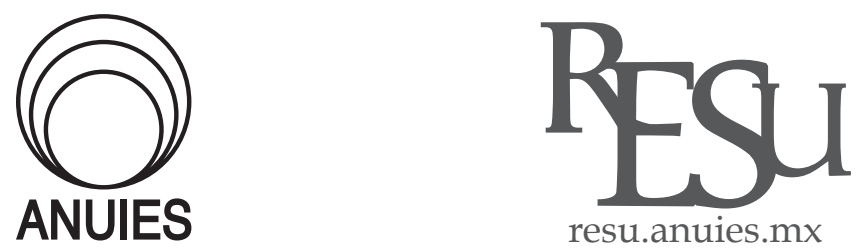

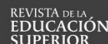

ARTí́CULO

\title{
Contextos, autonomía y formación de grupos de teatro en Puebla
}

\section{Contexts, autonomy and formation of theater groups in Puebla}

\author{
Jaime Torija Aguilar* \\ * Benemérita Universidad Autónoma de Puebla. Correo electrónico: jaime_torija@hotmail.com \\ Recibido el 29 de marzo de 2018; aceptado el 14 de junio del 2018.
}

\begin{abstract}
Resumen
Una de las estrategias que utiliza el individuo para lograr sus propósitos es la conformación de grupos, que tienen como principales características la empatía, el sentido de pertenencia, el respeto y la autorrealización. Lograr la grupalidad requiere enfrentarse a la fuerza del poder que incide en las conductas sociales, y al mismo tiempo, la capacidad de reconocer la autonomía como instrumento para la realización de sus proyectos. En este trabajo se hace referencia a algunos factores adversos, sustentados por el poder, y trata también de la capacidad que muestran los egresados de la carrera de Arte Dramático para recuperar su autonomía y con ello superar tanto la incertidumbre laboral, como la pérdida de identidad y de sentido.
\end{abstract}

Palabras clave: individuo, poder, autonomía, grupos 


\begin{abstract}
One of the strategies used by the individual to achieve their wishes is to form groups that have, as a condition, empathy, a sense of belonging, respect and self-realization. Achieving the group requires facing the force of power that affects social behaviors and, at the same time, the ability to recognize autonomy as an instrument for the realization of their projects. This paper refers to some adverse factors, supported by the power and the ability to recover the autonomy of graduates of the Dramatic Arts career to overcome job uncertainty, loss of identity and meaning.
\end{abstract}

Keywords: individual, power, autonomy, groups

\title{
Introducción
}

$\mathrm{C}$ uando la realidad y el deseo del individuo están limitados o se encuentran amenazados por una sociedad que representa el poder por medio de imposiciones institucionales, legislativas o axiológicas, éste busca mecanismos que reorienten nuevamente sus propios proyectos para realizar lo que verdaderamente quiere ejercer. Podríamos afirmar que la sociedad hace a los individuos, sin embargo, ellos pueden penetrar en la blindaje social para transformarla (Castoriadis, 2005), como una de las formas que utilizará para realizar sus deseos, recobrar su identidad y su sentido.

Una de las estrategias que el individuo ha utilizado para conseguir sus propósitos es la de conformar y participar en grupos que tienen, como condición anticipada, empatía y objetivos comunes. La agrupación es una característica de la naturaleza humana. Algunos seres vivos se congregan para sobrevivir, el ser humano no es la excepción, pues se une para preservarse como especie y para socializar; la unión es, en consecuencia, una de las estrategias básicas para existir. La condición social es la que le ha permitido al individuo perdurar en el mundo propio que ha conformado pese a su debilidad física si le compara con otros seres vivos; el humano, finalmente, tiene una morfología limitada en fuerza y habilidad, características fisiológicas que inducen a sospechar que pudo haber sido un accidente dentro del desa- 
rrollo biológico. Como individuo aislado sería un número más de las especies en extinción, sin embargo, la formación social, que al mismo tiempo ha permitido el desarrollo mental, es el factor al que se le atribuye su salvación y su sobrevivencia. Asimismo, es el que provee de las necesidades básicas del hombre como la "vida, inmunidad y seguridad, pertenencia y afecto, respeto y auto-realización" (Maslow, 2007: 13), elementos que son indispensables para la cohesión y la unidad, necesarios para identificarse como individuos.

Así como la sociedad le da al sujeto una vía de interpretación de sentido y de identidad, los "pequeños grupos" insertos en ella como las comunidades, la familia, los distintos gremios, las congregaciones religiosas y educativas, entre otras, también cumplen una función de preservación, de reconocimiento y de integración desde la singularidad; son, finalmente, un apéndice de la sociedad misma que tendrían que fortalecer el desarrollo individual para la realización del sujeto. Es, por lo tanto, condición innata que el hombre se rodee, en contextos ideales, de un medio adecuado que le permita su realización existencial.

No obstante, en el desarrollo de la humanidad se han presentado obstáculos culturales que han limitado la realización plena de los individuos. Vemos como ejemplo la modernidad, cuyos objetivos originalmente estuvieron dirigidos al encuentro del progreso y la felicidad; sin embargo, el incumplimiento trajo consigo vacíos, pérdida de valores, desarraigos, detrimento de principios e identidades, los cuales se agudizarían en el último tercio del siglo xx y lo que va del siglo XxI. Actualmente, el sujeto vive una cierta dosis de individualización y de indiferenciación (Simmel, 2004) que se manifiesta en sensaciones de soledad, de vacío, de aburrimiento y de desintegración familiar o gremial. Ante dichas incidencias, el individuo busca formas de convivencia - grupos - que puedan darle reconocimiento, seguridad y armonía; es decir, un equilibrio entre la individualización y la socialización.

El interés por el estudio de los grupos, ya sea en sectores laborales, religiosos, artísticos o educativos, se expande en la medida en que se diversifican los factores que detonan el impulso por congregarse. Algunas causas se deben a la necesidad de impulsar la productividad a través de organizaciones e instituciones gubernamentales, empresariales, educativas o de salud, que buscan un mayor rendimiento laboral y financiero específicamente para incrementar el capital; otras, por el deseo de empatizar en creencias y cultos religiosos. Vista desde otra perspectiva, la necesidad de formar grupos también se incentiva por los numerosos desequilibrios individuales (enfermedades psíquicas, problemas existenciales, pérdida de la identidad, desviaciones del yo, etc.), que empujan al reconocimiento del ser. El estudio de grupos, en consecuencia, tiene diferentes ángulos, con diversas tendencias y objetivos. 
Sin embargo, para lograr la iniciativa de llevar adelante la participación grupal, es necesario detenernos previamente en dos elementos importantes que están íntimamente relacionados: el primero es señalar, como elementos representativos del poder, algunas condiciones adversas, básicamente represivas, que la sociedad institucionaliza a partir de mediados del siglo xx. Dichas condiciones son políticas, sociales y axiológicas, las cuales repercuten en los ámbitos del conocimiento, de la educación y en la esfera familiar, a través de los valores, hábitos y costumbres. Otro de los elementos necesarios que habrá que preponderar, como segundo punto, es el impulso del individuo por ejercer su autonomía, para la realización de sus deseos, lo que implica sublevarse ante el poder implícito de la sociedad, lo cual ha guiado a los sujetos a la renuncia de su propio mundo:

El individuo social se constituye así interiorizando el mundo y las significaciones creadas por la sociedad, interiorizando explícitamente fragmentos importantes de ese mundo e implícitamente su totalidad virtual por las alucinaciones interminables que unen magmáticamente cada fragmento de ese mundo con los otros (Castoriadis, 2005: 50).

No hay una conciencia por romper con el dominio social hasta que se encuentran la creatividad y el sentido propios que el individuo desea poseer, en el que se adquiere una conciencia del yo, permitiéndose, entonces, la libertad de ejercer libremente y con sentido sus deseos, ideales y objetivos. Parecería difícil concebir que ante la imposición del poder cualquier intento por superarlo fuera imposible; no obstante, la posibilidad de romper con los obstáculos se vislumbra como una realidad, la cual puede ser ejercida desde cualquier flanco, ya sea de forma individual como colectiva (Foucault, 1986). Uno de los caminos acordes es a través de la conformación de grupos.

En este trabajo se hace referencia a algunos factores adversos que inciden en las decisiones que toman los posibles estudiantes de teatro y los egresados, quienes se enfrentan a la incertidumbre laboral; es decir, que independientemente de ser una profesión que requiere del trabajo grupal, también es necesario para su realización existencial. El interés surge por algunos factores propios de la localidad, los cuales pudieran ser fenómenos significativos dentro del ámbito de las artes escénicas que, como significaciones imaginarias sociales, marcan nuevas formas y hábitos en la concepción del teatro, tanto en el público como en el propio artista. Estas causas, que han incidido en los juicios y en los hábitos culturales de la población, son adjudicadas por la conducta de los individuos que eligieron encontrar su sentido de vida en las artes escénicas; elección nada fácil si se consideran las diferentes situaciones adversas a las que se enfrentan, sobre todo en una sociedad como es la 
poblana, en la que impera el reconocimiento de los individuos a partir de sus condiciones materiales y de consumo (como expectativa de realización) así como de sus valores éticos y morales, siempre que se conduzcan a través de directrices conservadoras basadas en los preceptos religiosos.

\section{Del tiempo libre a la profesionalización}

Desde la perspectiva de este trabajo, la elección de algunos individuos por dedicarse a las artes escénicas como profesión, tiene un punto de partida que resulta necesario considerar para encontrar la justificación que impulsa a valorar el sentido de la existencia a través de la actividad profesional, especialmente cuando las artes escénicas pasan a formar parte del curriculum universitario. Esto quiere decir que la actividad teatral, al proyectarse como licenciatura en las universidades públicas y privadas, exige al individuo una reflexión exhaustiva de sus objetivos, acciones y deseos porque es, finalmente, lo que le permitirá sentirse incluido responsablemente en el tejido social que, a su vez, será reconocido a través de su propia imagen: un individuo realizado profesional y productivamente que cumple con un servicio social. Es la profesión, sea de cualquier disciplina, la que permite otorgarse el derecho de hacer sus labores propias; es, finalmente, cumplir con las tareas que le incumben como "único, definitivo y esencial" (González, 1994: 26). La profesión es una necesidad para que el individuo encuentre su realización que deviene por su vocación, ya que espera dedicarle toda la vida a su actividad:

[Y para que] se identifique con las pautas ideales de su profesión, se sienta en profunda hermandad con los demás profesionales de su rama, rompa con la creciente dicotomización entre tiempo laboral y tiempo de ocio, dedicando a su profesión y al enriquecimiento de sus conocimientos y técnicas profesionales buena parte de su tiempo libre, y no abandone jamás su profesión, so pena de enfrentarse con el estigma de traidor o fracasado, en ciertas profesiones, si lo hace. El convencimiento profundo y la adhesión personal a la profesión como vocación puede desembocar a veces, sobre todo si se suman o intervienen otros factores (poder, prestigio), en una cierta sacralización de la profesión (González, 1994: 27).

Lo anterior nos obliga a establecer una diferencia entre la actividad teatral que proviene de individuos que han ejercido dicho quehacer motivados por el gusto, el talento, el impulso creador, pero con profesiones y actividades laborales ajenas al arte dramático, con respecto a los sujetos que se formaron y se forman profesionalmente en dicha actividad. Si partimos del hecho que en 
la diferencia se conciben los objetivos y los anhelos de vida, no se dudaría de la entrega, de la capacidad y de la calidad para ejercer dicha labor histriónica de parte de artistas que se formaron a través de la experiencia o de cursos teatrales; sin embargo, la razón de ser de los estudiantes y profesionistas de teatro marca la diferencia, pues su sentido de existencia, el encuentro con su identidad y los valores se legitiman a través de la profesionalización académica. Si antes de la profesionalización la actividad teatral sólo se miraba como una actividad pasajera o temporal, ahora las aspiraciones de su realización se verán respaldadas por la dedicación plena y la legitimización social.

Es necesario aclarar las diferencias sustanciales entre los grupos que desarrollan las actividades escénicas en Puebla antes y después de la profesionalización; es decir, los individuos que integraron grupos en las décadas anteriores a los años noventa del siglo xx y los que se crearon en el proceso y el término de su profesionalización a partir de 1997, año en que se formó la Licenciatura en Arte Dramático en la Benemérita Universidad Autónoma de Puebla (BUAP). Muchos de los actores poblanos de los años setenta y ochenta laboraban en oficinas gubernamentales, en el magisterio o eran estudiantes de diversas profesiones, algunos formados en talleres artísticos o en Casas de Cultura; buscaron el teatro como un medio para levantar la voz contra las represiones constantes del gobierno o de la moral conservadora de la sociedad poblana o, simplemente, como una actividad creativa. Estos grupos de teatrales no "vieron" a la actuación como una profesión, ni como una actividad permanente que les pudiera solventar sus necesidades económicas, para ellos el tiempo dedicado a las actividades escénicas era el que les quedaba completamente libre. En estos actores no hay una reflexión subjetiva que reclame a las instituciones una nueva organización para atender sus proyectos artísticos (becas, subsidios, presupuestos, espacios).

En cambio, a partir de 1997, cuando se profesionalizaron las artes escénicas en la BUAP, en el imaginario del individuo se construyó paulatinamente una nueva percepción (paradigma) de la actividad teatral, en la que se deposita la esperanza de lograr la realización personal a través de una actividad que socialmente se consideraba de poca importancia, infructuosa económicamente e incierta en el plano laboral. No obstante, para estas nuevas generaciones la actuación será una actividad especializada en la que se invertirá tiempo, dinero y desgaste emocional, entonces es cuando "los profesionales reclaman más tarde recompensas económicas y sociales” (González, 1994: 29).

Al profesionalizarse las artes escénicas, al sujeto se le devela una realidad contraria a sus expectativas, pues se enfrenta a una serie de eventos externos e internos que obstaculizan su decisión por estudiar dicha carrera artística. En las instituciones sociales (educativas, religiosas), así como en el ámbito 
familiar, el estudiante encuentra un entorno social adverso a su proyecto de vida a pesar de estar cursando una carrera profesional. Una de las primeras objeciones familiares es reprobar el paso de una actividad artística que fue "recurrente" y que le permitía al joven distraerse en las horas libres, a la de convertirse en una profesión.

$\mathrm{Al}$ individuo, entonces, se le cuestionan sus inclinaciones artísticas al llevarlas al plano profesional porque, hay quienes consideran que las artes "no son económicamente redituables". En una sociedad en donde las divisiones sociales están perfectamente diferenciadas $y$, como consecuencia, se enaltecen las posesiones materiales y la moral conservadora, no cabe la posibilidad de elegir como formación profesional una actividad considerada poco productiva. La presión social y familiar es determinante; muchos de los aspirantes a las artes sacrifican este deseo a pesar de ser la vocación acertada.

Ante dichos conflictos el individuo tiene dos opciones: o deserta a su vocación (con las consecuencias que trae consigo llevar una vida insatisfecha y con un alto grado de frustración), o se antepone a las adversidades para el logro de sus objetivos y la realización personal. Al optar por esta última, el profesionista necesariamente tendrá que buscar como una forma de sobrevivencia la empatía de los demás individuos afines para integrar un grupo que pueda contrarrestar las afectaciones físicas y emotivas, así como para fortalecer su identidad y su quehacer profesional:

En la medida en que uno hace de la propia experiencia la piedra de toque de la verdad, uno busca a aquellos con quienes se tiene una experiencia común para hallar significados comunes. En esta medida, el surgimiento de las generaciones y el sentido de la generación es el centro distintivo de la identidad moderna (Bell, 2006: 96).

Aquí la vinculación mutua se vuelve un soporte necesario porque en ella encuentran un sentido de pertenencia y se visualizan como un todo para hallar una mutua identidad en creencias y semejanzas que, al mismo tiempo, los protege de la soledad y del desamparo. "[...] contra los ataques del mundo externo y del mundo interno, el grupo propone un sistema de protección y defensa a cambio de un contrato de pertenencia permanente a él" (Kaës, 2000: 12-13).

Es importante entender cómo los artistas dedicados a las artes escénicas, al expresar su capacidad de resistencia (a través del grupo) para no doblegarse al rechazo social, familiar y a las intolerancias gubernamentales y empresariales, están, al mismo tiempo, contribuyendo a la generación de nuevos hábitos culturales mediante la apertura de nuevos espacios alternativos. Esto puede apreciarse en el incremento de diversos grupos que presentan 
variadas propuestas que, finalmente, despiertan el interés de un público con mayor capacidad crítica.

Cabe aclarar que no se están generalizando actitudes y finalidades de actores formados por diferentes caminos; en el caso de los actores no formados en las aulas universitarias, han hecho de la actividad teatral su modo de vida (incluso en la actualidad), ya sea porque la cercanía de la Ciudad de México les permitió seguir desarrollándose o porque su práctica ininterrumpida les ha aportado reconocimiento y constancia laboral. En el caso de los profesionistas teatrales, se puede asegurar que el poder de la adversidad ha contribuido a que muchos de los estudiantes terminen por desertar de la carrera. En este trabajo se busca reconocer la resistencia de los pocos actores que alcanzan mantenerse en circunstancias adversas y consiguen, a través de la autonomía y perseverancia, lograr sus objetivos.

\section{Contextos adversos}

Las condiciones externas son factores determinantes que influyen en las decisiones de los profesionistas de las artes escénicas, éstas traen como consecuencia la renuncia o la aceptación a la verdadera vocación. Se puede afirmar que el proceder de las personas está motivado, positiva o negativamente, por las condiciones que le son adversas. Por un lado, pueden llevarlas hacia la destrucción de las esperanzas y los objetivos trazados o, en un mejor escenario, inducen a afianzar las decisiones que les permitirán lograr la realización personal.

Cuando el contexto que rodea a los artistas poblanos se caracteriza por operar de forma negativa en el encuentro de su realización personal (la capacidad de elegir una profesión), la diversidad de acontecimientos puede ser suficientemente determinante para doblegar cualquier intento de sublevación, ya que las adversidades se encuentran en el centro medular del desarrollo humano, y van desde la concepción de la realidad que pasa por el matiz del método filosófico (la inmanencia del objeto) hasta aspectos políticos, sociales, económicos y culturales en los que se involucran las instituciones sociales, familiares y religiosas.

Al hablar de poder se está haciendo referencia a una diversidad de elementos que se entretejen en un sistema complejo, y se manifiestan, como dice Michel Foucault, en los "aparatos estatales, en la formulación de la ley, en las hegemonías sociales"; es decir, en una variedad de unidades: "El poder está en todas partes; no es que lo englobe todo, sino que viene de todas partes 
[...] no es más que el efecto de conjunto que se dibuja a partir de todas esas movilidades, el encadenamiento que se apoya en cada una de ellas y trata de fijarlas" (1986: 113).

Como se ha mencionado, el poder se encuentra en la diversidad de ámbitos, por ejemplo, en la relevancia que la tecnología concede a la ciencia por los intereses que el capitalismo reclama. La división entre las ciencias y las artes, inducida por las formas de concebir la realidad entre la razón y los sentidos, fue y ha sido un factor determinante para minimizar a los individuos que se inclinan por dedicarse a las actividades artísticas. Del mismo modo, se suman los cambios en los símbolos y en las formas de la estructura de la sociedad que obedecen, primero, a la transformación demográfica (concentración en los centros urbanos) y, segundo, a la aparición de una sociedad de consumo. Asimismo, la propia historia de la ciudad de Puebla tiene como ingrediente sustantivo la marcada división de las clases sociales y el control moral que ejerce la Iglesia católica. Dichos aspectos inciden en el sistema educacional "obligando" a los individuos a participar en una carrera de apariencias que denote poder económico y una conducta tradicionalista e intolerante a cualquier "desviación" sexual. Estas actitudes ejercen presión en la toma de decisiones cuando los jóvenes tratan de dirigir sus objetivos. La gran diferencia entre decidir su vocación por sí mismos o dejarse influir por los elementos externos adversos está en lograr o no su realización.

Otro aspecto que cabe mencionar, es la idea que se tiene del teatro y de los actores. Históricamente se ha visto al teatro como una expresión artística que se subordina a los dictados del poder. Se pueden mencionar, por ejemplo, las persecuciones que sufrían los actores de la Commedia dell'Arte por sus inclinaciones a la burla y la improvisación, o la prohibición de los autos sacramentales por la mezcla de asuntos profanos y religiosos (Oliva y Torres, 2005). En México no fue un asunto menor el Teatro de Revista en el que se presentaban, a través de la sátira y la burla, a los personajes políticos de época revolucionaria, lo que provocaba clausura de teatros, persecución y cárcel a directores y actores; asimismo, conviene mencionar que el teatro no comercial que se presentó antes y después de la Revolución (1900-1920) sufrió las mismas represalias. En términos generales, en el imaginario de la sociedad actual prevalece la percepción de que la actividad actoral está empañada de conductas irreverentes e inmorales. Veamos algunos eventos que se consideran significativos, los cuales aún son vigentes en el espíritu de la sociedad, sobre la idea que se tiene de los actores. 


\section{Ciencias y artes}

Entre los elementos adversos destaca la ancestral división (en los albores de la modernidad) que marcó la polaridad entre la ciencia y la tecnología con las humanidades y el arte, la cual aún irrumpe en el imaginario de la sociedad, y en la que se sobrevalora a la razón en contracorriente al desprecio de los sentidos. El lugar que se le daba a la ciencia, y aún hoy se le sigue dando, es de privilegio, ubicándola como la gran dominadora del mundo al concebirla como la medida de todas las cosas. Dicha posición le da un poder ilimitado al cálculo, y está apoyada por la técnica para objetivar lo vivo (la tierra, la naturaleza).

La técnica moderna induce a des-ocultar y producir, mas no a manipular (como en la antigüedad y en la Edad Media), confeccionar o "aplicar medios" (Heidegger, 1997: 122). Este “des-ocultamiento" es la labor esencial que la técnica realiza para llevar a cabo una liberación de la energía y, de esta forma, explotar a la naturaleza (Heidegger, 1997). Des-ocultar le da a la técnica un papel prepotente que permite objetivarse sobre la tierra, y al mismo tiempo, distanciar al hombre del descubrimiento que ejercía sobre ella; hay un distanciamiento de lo humano, generado por la técnica, respecto de la tierra. La producción técnica, que en algún momento fue dominada por el hombre, ahora escapa de sus manos, ya no puede expresarse de manera individualizada sino que se ha introducido a la esencia misma del hombre como sociedad.

El dominio de la técnica, que se expresa en la producción y que permea en todos los ámbitos de la sociedad, desdeña las actividades relacionadas con las humanidades y las artes porque se ciñen a una "reflexión meramente especulativa, ajena a operaciones de verificabilidad y contrastación empírica" (Espina, 2004: 12); esto se opone a la idea de "la verdad", del conocimiento, de la eficiencia y de la eficacia. En consecuencia, las humanidades y las artes no se pueden considerar disciplinas que conduzcan al progreso económico porque no buscan dar solución a las necesidades que la sociedad requiere como son el bienestar económico y el confort.

Esta supremacía proporcionada a la técnica trae consigo divisiones radicales entre las disciplinas y en las profesiones impartidas en la educación superior. Es evidente que las carreras tecnológicas en universidades públicas y privadas serán mejor atendidas en cuanto a la infraestructura que requieren, y en otorgarles un mayor presupuesto para sus actividades; en contraste, las humanidades y las artes muchas veces no encuentran las condiciones adecuadas para su desarrollo. Dichas diferencias repercuten en la percepción 
que la sociedad se forma de las profesiones; en consecuencia, se atribuye el derecho de valorar a los individuos a partir de la carrera que eligen.

Optar por una profesión que recaiga en las humanidades o en las artes, como es el caso de arte dramático, equivale a "renunciar", según el prototipo de productividad que la sociedad se ha formado, a una vida con estabilidad económica. Hay, de parte de las instituciones gubernamentales, sean federales o estatales, un marcado desdén y desacreditación de las actividades culturales y artísticas, lo cual se refleja, por ejemplo, en el poco presupuesto que se destina a dicho rubro, así como en la raquítica remuneración por el trabajo, por la falta de público en las presentaciones teatrales, entre otras cosas.

\section{La sociedad de masas}

Los bienes materiales se colocan en los deseos obsesivos de la sociedad de mediados del siglo xx. En la medida en que se desarrollan el capitalismo, la urbanización y la tecnología, la sociedad transita de productor a consumidor. En México se da una vertiginosa transformación en las ciudades por una fuerte concentración poblacional dejando a las zonas rurales semidespobladas y con nulas posibilidades de progreso. La conglomeración humana se refleja en las actividades cotidianas (escuelas, centros comerciales, etc.); el individuo se pierde en el anonimato, se mediatiza, es decir, se homogeniza "se siente 'como todo el mundo' $y$, sin embargo, no se angustia, se siente a sabor al sentirse idéntico a los demás" (Ortega y Gasset, 2002: 113). Dicho fenómeno no es algo que pudiera desvanecerse a corto plazo, al contrario, su presencia promete un mayor crecimiento poblacional y una permanencia durante muchos años. Su aparición, como fenómeno social, crea las condiciones para introyectarse en todos los ámbitos de la sociedad, sean estos ideológicos, estéticos, sociales, económicos, culturales y éticos, teniendo como base primordial el consumo. Los objetivos instalados en el imaginario se encuentran en el éxito económico de los individuos a través de la obtención de bienes materiales para ser "un miembro de una comunidad de consumo" (Bell, 2006: 75).

Alienarse a la lógica que ofrece dicha sociedad "garantiza" que se logre alcanzar la felicidad "... a través de la publicidad, el crédito, la inflación de los objetos y los ocios, el capitalismo de las necesidades ha renunciado a la santificación de los ideales en beneficio de los placeres renovados y de los sueños de la felicidad privada" (Lipovetsky, 2005: 50). Cualquier intento por alcanzar ideales que no se encuentren dentro de los parámetros del consumo será descalificado por los valores que la sociedad de masas ha implantado ya que la formación de los sujetos se va alienando a la estructura social existen- 
te. Es claro que la sociedad de masas hace que difícilmente se logre la divergencia de los individuos que la conforman, pues el dominio de la ideología opera con gran efectividad:

El sistema social dominante funciona con suavidad destilando en el sujeto la convicción de que sus decisiones son libres, mientras que, según la ideología como discurso, están completamente constituidas por el sistema social en interés del orden dominante. El discurso suministra apoyos al sujeto acomodaticio, a la espera de la elaboración de los roles, valores, elecciones y creencias del orden predominante (Carroll, 2002: 326).

Vemos que la sociedad de masas aparentemente nos permite tener la libertad de acomodarnos en el camino que nos guíe hacia la realización y el encuentro de uno mismo; sin embargo, más allá de las apariencias se encuentra un sistema social complejo, guiado por el capitalismo, que produce "modelos humanos heterodirigidos" (Eco, 1981: 50), restringe los deseos e impulsos de los individuos que luchan contra el status quo. Es el caso de los actores formados en la universidad que salen de los cánones del modelo establecido, son ellos quienes buscan sentido e identidad en la profesión que es considerada por la sociedad como una carrera poco lucrativa. Los estudiantes viven el desaliento cuando se enfrentan a todo el aparato publicitario que despliega el sistema para alentar sus valores. El cine, la radio, la televisión, la internet, etc., se congregan para enviar a los consumidores y a todos los rincones de la sociedad, sus gustos, sus emociones y su forma de concebir la realidad. Por lo anterior, cualquier "esfuerzo personal para la posesión de una nueva experiencia queda desalentado" (Eco, 1981: 48) y empuja hacia una actitud pasiva que produce desasosiego.

\section{La educación superior}

En el transcurso de las dos últimas décadas se ha visto la creación de la carrera de arte dramático en diferentes universidades públicas (tradicionalmente sólo la profesionalización se daba en la Universidad Veracruzana y en la Universidad Nacional Autónoma de México); la BUAP incorporó dicha licenciatura en 1997, época en que las instituciones federales aplicaron reformas universitarias y limitaciones presupuestales que respondieron a las políticas y las inercias empresariales y del mercado, lo que obliga a aplicar los principios de eficiencia, de eficacia y de calidad que trastocan ineludiblemente a las expresiones artísticas. Por un lado, es necesario observar que en los últimos años se reconocen los esfuerzos y las buenas intenciones de la universidad 
por crear una infraestructura adecuada a las necesidades de los estudiantes para el desarrollo de sus potencialidades; no obstante, los egresados que logran formar grupos se enfrentan, dentro de la misma universidad, a un incipiente apoyo para sus presentaciones.

Los espacios se rentan preferentemente a los artistas y grupos comerciales que logran cubrir las cuotas que se cobran para sus presentaciones porque esto implica mayores ingresos. En un país donde el presupuesto de las universidades ha disminuido como resultado de la poca financiación de los gobiernos neoliberales que empujan hacia la mercantilización, se puede entender la necesidad de buscar ingresos propios. No obstante, se observa que hay pocas oportunidades para los grupos incipientes que no pertenecen a compañías ya establecidas en los foros más emblemáticos, en horarios que garantizan mayor afluencia de públicos.

Más allá de las justificadas estrategias diseñadas para generar ingresos, el fenómeno del mercado ha ido mermando la "idea y [el] sentido de comunidad de que gozaba la universidad" (Di Napoli, 2010: 194), en donde originalmente se generaba la crítica y la reflexión de los sucesos sociales, económicos e ideológicos. Son los grupos que egresan de sus propias aulas los que permiten, por el espíritu universitario que genera la autonomía, dinamizar el encuentro con la sociedad y crear el "debate crítico, la interpretación y la reflexión de la de la cual puede surgir tanto el acuerdo como la oposición" (De Napoli, 2010: 197). En la realidad encontramos, en los foros principales, más presentaciones de artistas moldeados por el mercado y para el consumo; en cambio, para el teatro experimental o llamado de búsqueda -integrado en su mayoría por profesionales universitarios - encuentra escasos espacios para desarrollar sus actividades.

\section{Valor ético y moral}

Como célula social, la familia absorbe y recrea los valores que la sociedad determina; la consolidación económica es uno de los objetivos más importantes. Cuando el joven ha tenido la oportunidad de estudiar y logra ingresar a la educación superior, la esperanza de los padres es que elija una profesión considerada como productiva, es decir, una actividad que se concibe como altamente demandada y bien remunerada, circunscrita en las áreas técnicas, científicas y algunas de las ciencias sociales. Se espera que los hijos sean exitosos económicamente; dicha expectativa impone al futuro profesionista una responsabilidad moral, social y familiar que, con frecuencia, constituye una pesada carga emocional. Con frecuencia, los padres eligen la carrera de los 
hijos sin pensar en el deterioro psicológico que ello implica. La interferencia de los padres en la elección de la profesión es una de las acciones más perjudiciales. Cuando Foucault (1992) pregunta acerca de la represión "más insoportable del estudiante de bachiller" (1992: 33), se responde como primera opción el de la autoridad familiar, sobre todo cuando "los padres que te imponen el Instituto como una etapa hacia una situación profesional determinada y que se esfuerzan por apartar de antemano aquello que pudiese perjudicar esta situación..." (1992: 33). La frustración, el vacío y la falta de sentido serán las consecuencias que se expresarán a mediano y largo plazos.

\section{El camino a la autonomía}

Cuando se hace referencia a la autonomía, se está hablando de un impulso del sujeto y de la sociedad. Aquí nos centraremos específicamente en el individuo, quien empieza a ejercer su autonomía cuando logra salir de la sujeción, anteponer sus decisiones, pensarse a sí mismo como motor de cambio, a pesar de las contrariedades que genera (reproches, amenazas, chantajes etc.) en la sociedad y en la familia. Existe una fractura radical con la alienación en la toma de decisiones; es decir, con ese "dominio por un imaginario automatizado que se arrogó la función de definir para el sujeto tanto su realidad como su deseo" (Castoriadis, 2013: 163). El romper con los lineamientos que la sociedad de consumo impone permite priorizar y alcanzar los deseos a través de la conciencia misma del individuo, y hace tomar "otra actitud del sujeto con respecto a sí mismo" (Castoriadis, 2013: 165); también implica la fractura con respecto a la coacción que la sociedad se ha encargado de introyectar en el imaginario. Es, por lo tanto, una acción de autonomía lo que ejercerá el individuo para el encuentro de sus propias acciones:

La autonomía del individuo consiste en el hecho de que otra relación se establece entre la instancia reflexiva y las otras instancias psíquicas, así como entre su presente y la historia mediante la cual se hizo tal como es, permitiéndole escapar a la servidumbre de la repetición, volverse sobre sí mismo y sobre las razones de sus pensamientos y los motivos de sus actos, guiado por la mira de lo verdadero y la elucidación de su deseo (Castoriadis, 2005: 65).

El actor profesional, al plantearse el proyecto de autonomía, está rebelándose contra la imposición como una necesidad de preservarse, para ello "debe evaluar positivamente lo que favorece su conservación y negativamente lo que la desfavorece" (Castoriadis, 2004: 58), asimismo, contraponerse a las 
expectativas que le depara una comunidad en donde la actividad escénica no tiene oportunidades en espacio, presupuesto o en compañías subsidiadas. Esto debido a las condiciones laborales que el neocapitalismo ha impuesto, pues impiden el reconocimiento de la labor artística en general. A través de la autonomía se ponen en duda los parámetros de las profesiones que la sociedad ha sobrevalorado cuando califica a estas de productivas o improductivas. La dignificación de la actividad teatral implica que el individuo reconozca su identidad, realice sus deseos y genere recursos económicos. Al mismo tiempo, la autonomía conlleva a una transformación social, pues se constituye algo nuevo en el imaginario de la sociedad que irrumpe con los esquemas ya establecidos. En el caso de la actuación, empieza a ser concebida como una actividad productiva debido a que se observa que cada año la demanda por ingresar a la carrera es mayor; las objeciones familiares para el estudio de las artes escénicas son menores, entre otros elementos.

El profesionista que ha concluido su formación universitaria se enfrenta a una realidad que difiere de su condición como estudiante; sabe que será necesario buscar el vínculo, las afinidades y la comunicación con los demás miembros de su comunidad para así tratar de asegurar su futuro que, sin el trabajo grupal, no podría lograr.

Dicha autonomía ha impulsado a los actores a agruparse y, al mismo tiempo, a radicalizarse en su profesión para crear estrategias creativas. Muchas de éstas se han dirigido a reconocer aspectos de la idiosincrasia poblana, lo cual les sirve de contragolpe para salir fortalecidos. Se observa con más frecuencia que las puestas en escena se inspiran cada vez más en la propia realidad poblana y se distancian de las tradicionales propuestas universales, las cuales son, finalmente, escenarios e identidades ajenos.

Cabe señalar que lograr la autonomía significa ir en contra de la fuerte inercia que la sociedad impone para que los individuos inmersos en las artes escénicas no reconozcan el poder que ejercen en la conciencia social, así como el poder que alcanzan al realizar el trabajo colectivo. Las limitaciones presupuestales, la falta de espacios o la devaluación de las actividades artísticas, son estrategias hermenéuticas creadas desde la concepción del capitalismo e incrustadas en el diseño de las políticas locales; no obstante, los cambios en el imaginario social se crean desde la subjetividad.

\section{El grupo teatral}

Cuando hay autonomía entonces se fortalecen los grupos y los individuos. La formación grupal para la presentación de obras dramáticas es el camino 
que logran encontrar los profesionistas en arte dramático para fortalecer sus convicciones, deseos y proyectos. $\mathrm{Al}$ anteponer sus aspiraciones, como una forma de encontrar su lugar en la sociedad, el individuo se está enfrentando al poder que por mucho tiempo lo mantuvo en una situación pasiva. Al agruparse, el sujeto se reencuentra a sí mismo y ve cómo se aleja de las diversas actividades que no corresponden a su profesión para lograr, entonces, redignificarse en su actividad artística. Esto no es un asunto menor en la medida en que se es reconocido por la sociedad como un sujeto productivo que genera conocimiento, cultura y sensibilidad estética; asimismo, implica ofrecer tiempo valioso para "cultivar con amorosa atención las propias experiencias interiores [...] y le garantiza celosamente una absoluta originalidad" (Eco, 1981: 45).

Es claro que la profesión actoral es de las pocas actividades que no pueden realizarse desde la individualidad, es un ejercicio que requiere de los demás para desarrollarse con plenitud y seguridad, además, favorece el encuentro de la potencialidad creativa, la cual se materializa al descubrir las diversas expresiones en la puesta en escena.

El trabajo grupal se debe centrar en el potencial creativo que impulsan la cultura y la sensibilidad que cualquier sociedad requiere. Si bien el contexto es un elemento que ha influido negativamente en el quehacer de los profesionistas dedicados a las artes, también es cierto que ha servido como impulso, para el reposicionamiento social a través del grupo. La multiplicación de dichos grupos se ha fortalecido paralelamente con los espacios en los que se presentan las obras dramáticas, lo que ha dado como resultado despertar el interés de nuevos espectadores que no recurrían a este tipo de espectáculos.

\section{Conclusión}

Cultivar la autonomía es un proceso que se vuelve necesario en los profesionistas de las artes escénicas para que logren desarrollar el trabajo que eligieron, sobre todo en un país que se somete a las leyes del mercado y en el que impera el hábito del consumo. Cuando los valores se alimentan por la cultura del individualismo, la posesión material, el reconocimiento de las actividades tecnológicas, entre otros elementos, la elección por las actividades escénicas induce forzosamente a reestructurar un sistema de vida. Esto incluye el cuestionamiento de los valores familiares, de las instituciones educativas y del propio sistema social, económico y político que han propiciado la adquisición de una identidad artificial y extremadamente inconsistente. La ideo- 
logía del poder que se manifiesta en diferentes ámbitos de la vida consigue difuminar cualquier intento por sustraerse de las condiciones que el mercado asigna; sin embargo, para superar esta situación se requiere, en primer lugar, lograr desarrollar una conciencia que capte los elementos que contaminan los objetivos buscados. Es entonces que se fortalecen los proyectos de vida para encontrarse con la identidad y el verdadero sentido del individuo.

La realización personal y profesional de los egresados de la carrera de teatro implica reconocer que la vinculación y la empatía son fundamentales para realizar el proyecto de vida. Esto ha originado que en la ciudad de Puebla y en algunos municipios conurbados - por ejemplo, en Atlixco y San Martín Texmelucan - se formen diversos grupos. Solamente en la capital poblana existen aproximadamente 30 grupos activos que se presentan en diversos espacios alternativos. Difícilmente podría pensarse en años anteriores al siglo XXI que puestas en escena se lograrían presentar en bares, cafés, vecindades o zonas periféricas de la ciudad. Sin embargo, la imaginación y la necesidad de los profesionistas por tener un espacio en la sociedad y erigirse como seres productivos, han impulsado la expansión y la dignificación del teatro. Esto puede apreciarse a través de una mayor asistencia del público, siendo éste quien también determina la transformación cultural y artística en la ciudad.

\section{Referencias}

Bell, Daniel (2006). Las contradicciones culturales del capitalismo. Madrid: Alianza Editorial

Castoriadis, Cornelius (2004). Sujeto y verdad en el mundo histórico-social. Seminario 1986-1987, La creación humana I. Buenos Aires: Fondo de Cultura Económica.

Castoriadis, Cornelius ((2005). Ciudadanos sin brújula. México: Ediciones Coyoacán

Castoriadis, Cornelius (2013). La institución imaginaria de la sociedad. México: Tusquets.

Carroll, Noel (2002). Una filosofía del arte de masas. Madrid: La balsa de la Medusa.

Di Napoli, Roberto (2010). “Identidades académicas y gestión. ¿Una misión imposible?", en Rué, Joan y Laura Lodeiro (eds.), Equipos docentes y nuevas identidades académicas, Madrid: Narcea.

Eco, Umberto (1981). Apocalípticos e Integrados. Barcelona: Lumen.

Espina Prieto, Mayra, "Complejidad y pensamiento social". Transdisciplinariedad y complejidad en el análisis social. Gestión de las Transformaciones Sociales, MOST, documento de debate $n^{\circ} 70$, UNESCO, (consultado el 23 de mayo de 2017), http:// unesdoc.unesco.org/images/0013/001363/136367s.pdf.

Foucault, Michel (1992). Microfísica del poder. Madrid: La Piqueta.

Foucault, Michel (1986). Historia de la sexualidad. 1-La voluntad de saber. México: Siglo XXI. 
González Anleo, Juan (1994). "Las profesiones en la sociedad corporativa", en Fernández Fernández, José Luis y Hotal Alonso, Augusto (Comps.). Ética de las profesiones. Madrid: Universidad Pontificia Comillas.

Heidegger, Martín (1997). Filosofía, ciencia y técnica. Santiago de Chile: Editorial Universitaria.

Kaës, René (2000). Las teorías psicoanalíticas del grupo. Buenos Aires: Amorrortu. Lipovetsky, Gilles (2005). El crepúsculo del deber. Barcelona: Anagrama.

Maslow H., Abraham (2007). El hombre autorrealizado. Hacia una psicología del Ser. Barcelona: Kairós.

Oliva César y Torres Monreal, Francisco (2005). Historia básica del arte escénico. Madrid: Catedra.

Ortega y Gasset, José (2002). El tema de nuestro tiempo. La rebelión de las masas. México: Porrúa.

Simmel, George (2014). Sociología: estudios sobre la formación de socialización. México: Fondo de Cultura Económica. 